\title{
Noncontingent and contingent no-choice intervals and concurrent performance
}

\author{
PAMELA G. REAL and SALLY L. HOBSON \\ Adelphi University, Garden City, New York
}

\begin{abstract}
Pigeons responded to changeover-key concurrent variable-interval variable-interval reinforcement schedules while there were intervals during which the changeover key was inoperative (no-choice intervals). In Experiment 1, a multiple schedule on the changeover key sig. naled choice and no-choice intervals. All subjects showed near-perfect discrimination during initial discrimination training and rapid reacquisition of discrimination following contingency reversals. In Experiment 2, the onset of no-choice intervals was unsignaled and contingent on interchangeover time. The temporal distribution of changeover-key responses conformed to the temporal distribution of choice intervals. The results of both experiments suggest that changeover responding is modifiable as a function of its immediate consequences. The results of Experiment 2, in particular, suggest that time or some correlate of time since the last changeover response can determine subsequent changeover behavior.
\end{abstract}

A general result of concurrent reinforcement procedures is that subjects distribute their responses and time among alternatives in approximate proportion to the amount of reinforcement available in each. This matching relationship has been well documented (see de Villiers, 1977). However, there is disagreement about the processes responsible for matching. Molar views (Baum, 1973; Herrnstein, 1970; Rachlin, 1978 ) assume that reinforcement establishes a general tendency to emit responses within a specified operant class. The temporal distribution of reinforcement is viewed as an experimental parameter that asserts its effect in broad relationship to behavior. The temporal distribution of selections [changeovers (COs)] among available alternatives is viewed as reflecting an essentially stochastic process (Herrnstein \& Heyman, 1979; Heyman, 1979; Heyman \& Luce, 1979). Molecular views (Shimp, 1969, 1975, 1982; Silberberg, Hamilton, Ziriax, \& Casey, 1978) assume that reinforcement establishes local response contingencies that may shape sequences or patterns of responding (Fetterman \& Stubbs, 1982; Shimp, 1982). Changeovers are viewed as a function of temporally correlated and discriminable changes in reinforcement as it covaries with behavior allocation. That is, it is assumed that subjects track local changes in reinforcement probability and distribute

Portions of Experiment 1 were presented at the annual meeting of the Eastern Psychological Association, Boston, 1977. Thanks are given to Aaron Brownstein and Ted Cochran for helpful comments on an earlier version of this manuscript. The first author, to whom correspondence should be addressed, is now at the Department of Psychology, Middlesex House, University of Massachusetts, Amherst, Massachusetts 01003. their choices so as to maximize momentary probabilities of reinforcement.

One of the issues involved, then, concerns the sensitivity of $\mathrm{CO}$ behavior to changes in reinforcement probability. Hale and Shimp (1975) demonstrated control of choice by temporally correlated changes in reinforcement probability in a discrete-trials procedure. However, Heyman (1979) showed that conditional probability of a $\mathrm{CO}$ as a function of run length is constant on interdependent concurrent variableinterval schedules, implying insensitivity of choice to local changes in probability of reinforcement. Citing apparent periodicities in the distribution of interchangeover times (ICTs) as evidence of a momentary maximization strategy, Silberberg et al. (1978) disagreed. The disagreements involved are not primarily empirical in nature, since Heyman (1979) and Silberberg et al. (1978) presented data that seem highly similar and yet arrived at opposing conclusions based on different theoretical positions.

Differences of opinion with regard to the operant nature of $\mathrm{CO}$ behavior are implicit in the theoretical positions represented above. There is little consensus with regard to whether individual choices or sequences of choices are determined by reinforcement contingencies and therefore behave as functional behavioral units (see Fetterman \& Stubbs, 1982, Nevin, 1979, and Shimp, 1982). However, several findings indicate that $\mathrm{CO}$ behavior is modifiable as a function of its consequences. Research has shown that $\mathrm{CO}$ behavior is sensitive to the suppressive effects of contingent shock and time-out (Todorov, 1971), to the discriminative control of stimuli correlated with availability of reinforcement (Pliskoff \& Green, 1972), and to the duration of minimum delays to reinforcement prescribed by the use of a change- 
over delay (COD) (Pliskoff, 1971; Silberberg \& Fantino, 1970; Stubbs, Pliskoff, \& Reid, 1977).

Stubbs (1980) showed that COs between two components that provide reinforcement during different halves of a "to-be-discriminated" interval are under the control of temporal patterns of reinforcement. He used a free-operant psychophysical procedure to assess temporal judgment. The temporal distribution of COs was clearly in accord with local properties of the reinforcement schedules. This finding suggests that the amount of time elapsed might serve as a discriminative stimulus for $\mathrm{CO}$ responding on concurrent schedules. If $\mathrm{CO}$ responding is modifiable as a function of its contingent events (i.e., punishment; Todorov, 1971) and is sensitive to local patterns of reinforcement (i.e., Stubbs, 1980), then it is possible that the CO response and the ICT may function as behavioral units. For the present, let us assume that the only immediate consequence of $\mathrm{CO}$ responding, in most concurrent procedures, is a change in schedule components and that the availability of reinforcement in an unattended component is an indirect or delayed consequence. To generalize the results of the studies cited above, it is likely that $\mathrm{CO}$ behavior is sensitive to a variety of experimental manipulations, including changes in the immediate outcome of a $\mathrm{CO}$ response. In fact, extinction for $\mathrm{CO}$ responding can be parsimoniously conceived as the failure of $\mathrm{CO}$ responses to alter schedule availability.

The present experiments address the acquisition of discriminative control over $\mathrm{CO}$ responding by discrete intervals of extinction for $\mathrm{CO}$ responding. Experiment 1 arranged a go/no-go multiple schedule on the $\mathrm{CO}$ key, permitting COs only when one of the stimuli was in effect. Experiment 2 arranged intervals of extinction for COs that depended on ICT duration. The onset of extinction periods was unsignaled and explicitly correlated only with the amount of time elapsed since the previous $\mathrm{CO}$ response. Thus, the experiments employed intervals of extinction for CO responses that were correlated either with a distinct exteroceptive stimulus (Experiment 1) or with the behavior of the subjects (Experiment 2). Procedurally, this allows for the assessment of the sensitivity of $\mathrm{CO}$ responding to operant contingencies without explicitly altering the correlation between COs and the independent variable that is presumed to maintain them (main-key reinforcement) and without necessarily altering the character of concurrent performance at other times in an experimental session.

\section{EXPERIMENT 1}

\section{Method}

\section{Subjects}

Four male white Carneaux pigeons, maintained at $80 \%$ of their adult free-feeding weights, served as subjects. They had had ex- perience with a variety of reinforcement schedules, but were naive with respect to concurrent schedules.

\begin{abstract}
Apparatus
A standard three-key pigeon pecking panel (BRS-LVE) mounted in a sound-attenuated chamber (BRS-LVE, SEC-002) provided the experimental enclosure. Only the center and right keys were used. Keys were transilluminated by $28-\mathrm{V}$ dc three-color stimulus units (BRS-LVE). A force of approximately $0.1 \mathrm{~N}$ was required to operate the keys. Masking noise was provided through speakers in the chamber and in the room housing the experimental chamber. Standard electromechanical programming equipment arranged the experimental events and recording from an adjacent room.
\end{abstract}

\section{Procedure}

Preliminary training. Pecks were shaped to the right key, which was designated the main key, and then reinforced on a variableinterval 30-sec (VI 30-sec) schedule (Fleshler \& Hoffman, 1962), in the presence of both main-key stimuli (red and green) for three consecutive sessions. The subjects were then reinforced according to a criterion of strict alternation between the white center key (CO key), which was previously unlit, and the main key. Only responses to the main key produced reinforcement.

Experimental training. During the first phase, pecks were reinforced on CO-key concurrent variable-interval 120-sec variableinterval 120-sec schedules (conc VI 120-sec VI 120-sec). Each response to the $\mathrm{CO}$ key alternated the schedules and the mainkey stimuli and initiated a 3-sec COD. Main-key responses were reinforced according to the prevailing schedule by 3-sec access to mixed grain. Sessions terminated following 60 reinforcements.

Phase 2 through Phase 4 (general description). A multiple schedule was in effect on the CO key during Phase 2 through Phase 4. In the presence of one stimulus $\left(S^{d}\right)$, responses on the $\mathrm{CO}$ key alternated the schedules and the main-key stimuli, as in the initial baseline condition. In the presence of the other stimulus $\left(S^{\Delta}\right)$ responses on the $\mathrm{CO}$ key had no scheduled consequences.

One-minute multiple schedule components were quasi-randomly alternated. During consecutive $S^{\Delta}$ cycles, the main-key stimuli were strictly alternated once per minute and a multiple VI 120-sec (red) VI 120-sec (green) (mult VI 120-sec VI 120-sec) schedule was in effect on the main key. During Phases 2 and 4 , the $S^{d}$ stimulus was white and the $S^{\Delta}$ stimulus was amber. During Phase 3 , the $S^{d}$ stimulus was amber and the $S^{\Delta}$ stimulus was white. Following Phase 4, all subjects were returned to the original baseline condition.

\section{Results}

Figure 1 summarizes performance for all subjects in all phases of the experiment. Each data point represents the mean of the last three sessions in a condition. The top left panel shows average $C O$ rates (changeovers/minute) in both components for Phases 1 and 5 and in $S^{d}$ for Phases 2-4. The bottom left panel shows average rates of responding on the CO key during $S^{\Delta}$ for Phases 2-4.

Three of the four subjects showed an increase in $\mathrm{CO}$ rate during the $\mathrm{S}^{\mathrm{d}}$ multiple schedule components of Phases 2-4 relative to $C O$ rates in the initial baseline condition. The increase above baseline $\mathrm{CO}$ rates was greatest in Phase 2. One subject (B-414) showed a decrease in average $\mathrm{CO}$ rates during Phase 3. All subjects showed good recovery of baseline $\mathrm{CO}$ rates during Phase 5. Rates of responding on the CO key during the $\mathrm{S}^{\Delta}$ components of Phases $2-4$ (bottom panel) were less than $0.70 \mathrm{CO} / \mathrm{min}$ for all subjects. 

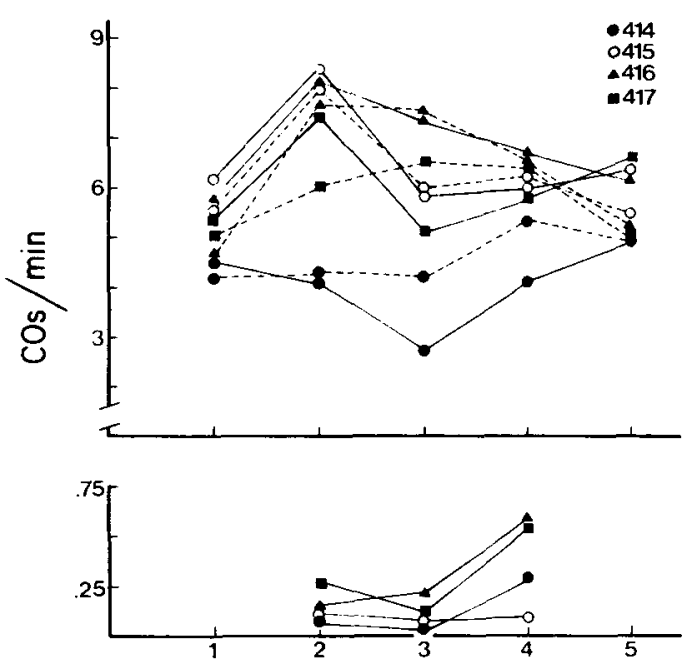

PHASE

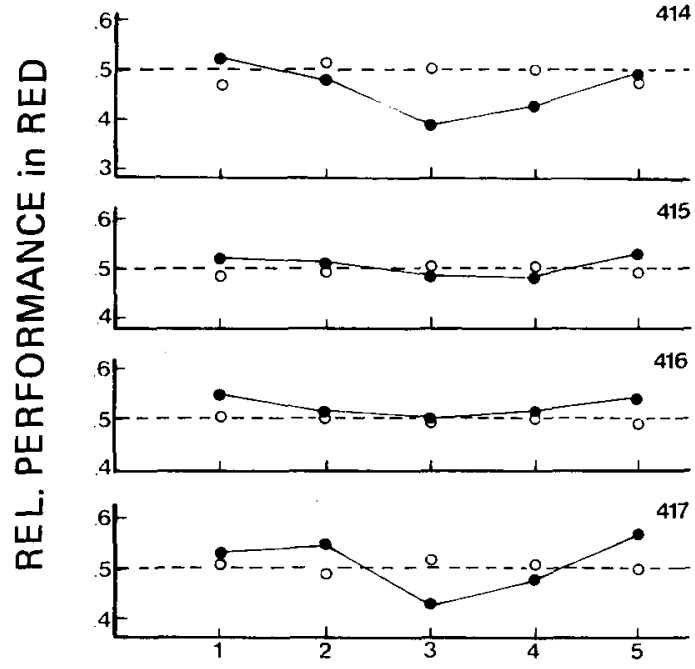

PHASE

Figure 1. Average changeovers/minute during a session for Phases 1 and 5 and during Sd for Phases $2-4$ in both main-key components (top left panel). Data from the red component are shown by the dashed lines; data from the green component are shown by the solid lines. Responses/minute to the CO key during $\mathrm{S}^{\Delta}$ for Phases $2-4$ (bottom left panel). Relative time allocation (filled circles) and relative reinforcements (open circles) in the red component for all phases of Experiment 1 (right panel).

The right-hand panel shows relative time allocation (closed circles) and relative reinforcements (open circles) in the red component. The dashed line at 0.50 represents hypothetical matching between relative time and reinforcements, given no deviation from programmed reinforcement. Two subjects (B-414, B417) allocated more time to the green component than would be predicted by relative reinforcements during Phase 3, but the other subjects showed good approximations to matching during all phases of the experiment. There were no obvious systematic relationships between discrimination training and molar response descriptions. Relative reinforcements deviated only slightly from what would be predicted on the basis of programmed rates of reinforcement.

Figure 2 shows discrimination indices [ $S^{d}$ rate $/\left(S^{d}\right.$ rate + $\mathrm{S}^{\Delta}$ rate); Herrick, Meyer, \& Korotkin, 1959] from Phases 2-4 for all subjects. Closed circles represent the mean discrimination index of two consecutive sessions. When the number of sessions in a condition was odd, the final three sessions were averaged to yield the last data point (indicated by an open circle). All subjects showed discrimination indices above 0.90 for a minimum of six sessions (three blocks) prior to a contingency reversal and showed discrimination indices above 0.75 within six sessions following a contingency reversal.

\section{Discussion}

Experiment 1 established stimulus-correlated differential consequences for CO-key responding on conc VI VI reinforcement schedules. The results of the experiment can be interpreted as suggesting that pigeons readily discriminate changes in the immediate outcome of $\mathrm{CO}$ responding (i.e., failure of the CO-key response to alter schedule availability). The present study found reduction in rate of responding to the $\mathrm{CO}$ key during discrete intervals (no-choice intervals) but no reduction in rate of $\mathrm{CO}$ responding during choice intervals. Furthermore, the no-choice contingency produced suppression of CO-key responding without altering the correlation of $\mathrm{CO}$ responding with subsequent reinforcement during choice intervals and without altering molar descriptions of concurrent performance during choice intervals. These findings, then, extend the generality of earlier research on the effects of $\mathrm{CO}$ contingent punishment (Todorov, 1971) and the effects of stimulus-reinforcement correlation (Pliskoff \& Green, 1972). Taken together, these data can be interpreted as suggesting that $\mathrm{CO}$ responding is sensitive to a broad class of experimental contingencies.

Experiment 1 scheduled no-choice contingencies quasi-randomly and independently of the behavior of the subjects. It, therefore, represented a departure from the type of contingency found in a typical concurrent procedure. In the usual concurrent schedule, the events that follow a $\mathrm{CO}$ response (i.e., the COD, reinforcement, etc.) are generally of brief duration and are correlated, at least to some extent, with the subject's behavior. In fact, momentary maximization theorists (Shimp, 1982; Silberberg et al., 1978) suggest that experimental events that are 

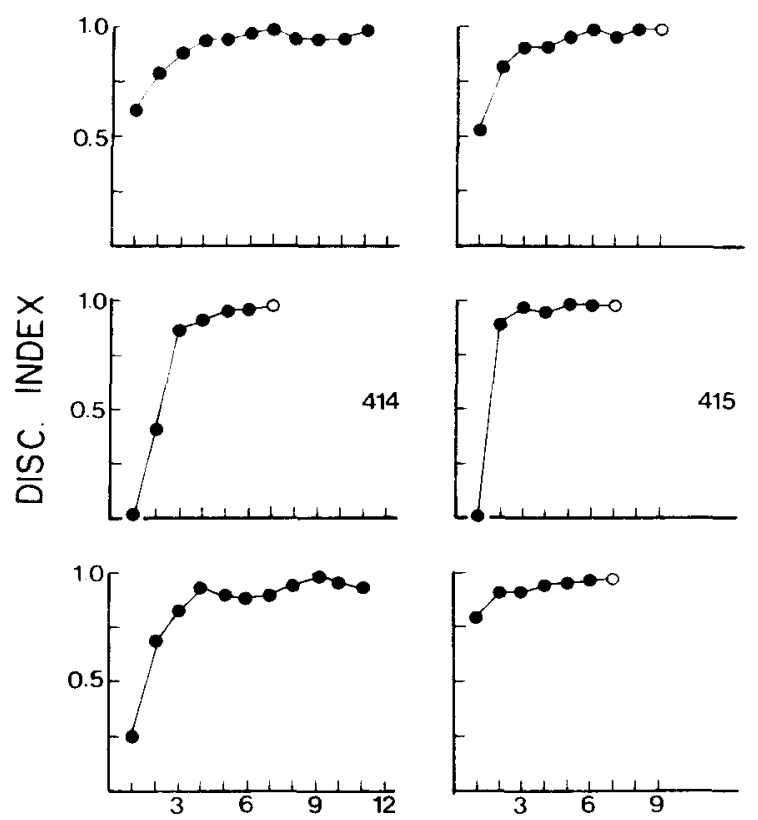

BLOCKS OF
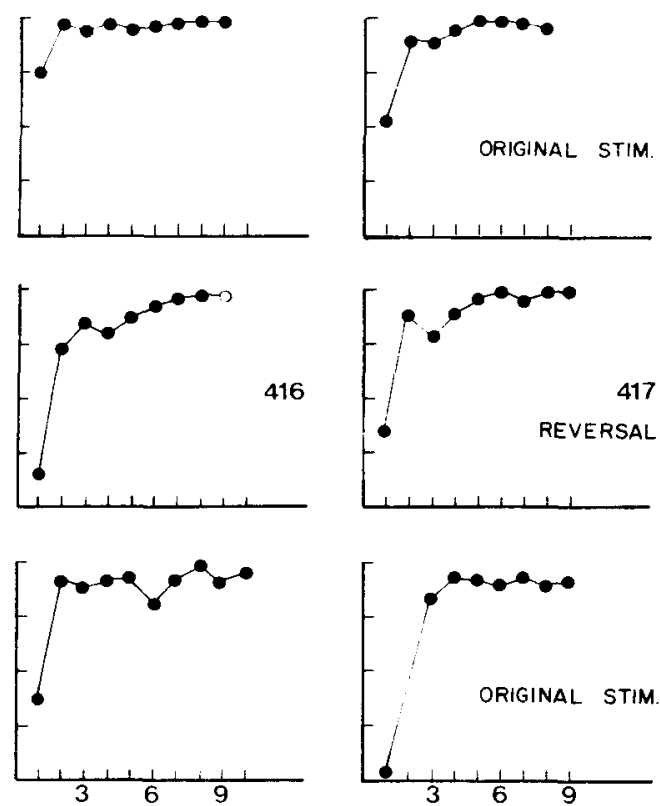

2 SESSIONS

Figure 2. Mean discrimination index over blocks of two (filled circles) or three (open circles) consecutive seasions for Phases 2-4 of Experiment 1.

correlated with ICT duration determine local time allocation on concurrent schedules. However, the sensitivity of ICT duration on concurrent schedules to contingencies other than reinforcement availability has not yet been explicitly investigated. In Experiment 2, no-choice intervals were contingent on ICT duration. In addition, Experiment 2 arranged brief no-choice intervals in such a way as to more closely approximate more typical concurrent procedures and to minimize changes in reinforcement density during no-choice intervals.

\section{EXPERIMENT 2}

\section{Method}

Subjects

Three male white Carneaux pigeons, maintained at $80 \%$ of their adult free-feeding weights, served as subjects. They had no previous experimental histories.

The apparatus and preliminary training were the same as in Experiment 1.

Experimental training. During the first phase of the experimental procedure, the subjects were reinforced on a CO-key concurrent variable-interval 60 -sec variable-interval 60 -sec (conc VI 60-sec VI 60-sec) schedule. Each response to the CO key alternated the schedules and the main-key stimuli and initiated a 2-sec COD. Main-key responses were reinforced according to the prevailing schedule by $3-\mathrm{sec}$ access to mixed grain. Sessions were terminated following 60 reinforcements.

Phase 2 through Phase 4 (general description). Intervals during which CO-key responses no longer alternated the reinforcement schedules were contingent on ICT duration during Phase 2 through Phase 4. Interchangeover times that fell within certain bounds (e.g., between 4 and $8 \mathrm{sec}$ ) would not change the main-key component; ICTs outside of these temporal bounds would change the component. Duration of the no-choice interval was fixed at $4 \mathrm{sec}$ for all conditions. The first $\mathrm{CO}-\mathrm{key}$ response during the nochoice interval changed the CO-key stimulus from white to amber. The key remained amber for the rest of the interval. Hence, the duration of the amber stimulus, which served as feedback for the first ineffective CO-key response, depended upon how much of the no-choice interval had elapsed prior to the first ineffective response. ${ }^{1}$ A stimulus change was correlated with the no-choice interval only if at least one CO-key response occurred during the interval. Responses to the $\mathrm{CO}$ key during the amber stimulus had no scheduled consequences. Reinforcement was available, as prescribed by the schedules, at all times.

During Phases 2 and 4 of the experiment, the no-choice interval was scheduled for ICT durations longer than $4 \mathrm{sec}$ and shorter than 8 sec. During Phase 3 of the experiment, the no-choice interval was scheduled for ICT durations longer than $6 \mathrm{sec}$ and shorter than 10 sec. Following Phase 4, the subjects were returned to the original schedule. Phases were terminated when performance stabilized for a minimum of three sessions.

One subject (B-103) was exposed to a procedure that required it to withhold responding during the amber stimulus in order to gain access to choice periods. This additional procedure was employed because this subject tended to respond perseveratively to the $\mathrm{CO}$ key during the amber stimulus. The first response to the $\mathrm{CO}$ key during the no-choice interval initiated a 4-sec period during which the $\mathrm{CO}$ key was amber and $\mathrm{CO}$ responses were ineffective. Successive responses to the $\mathrm{CO}$ key during the amber stimulus reset the 4-sec interval. In other respects, this procedure was identical to Phases 2 and 4 (4-8-sec no-choice interval).

\section{Results}

Figure 3 shows the mean conditional probability of a response to the $\mathrm{CO}$ key as a function of the amount of time elapsed since the previous effective CO (ICT per opportunity). Data for the red component are on the left panel; data for the green component are on 

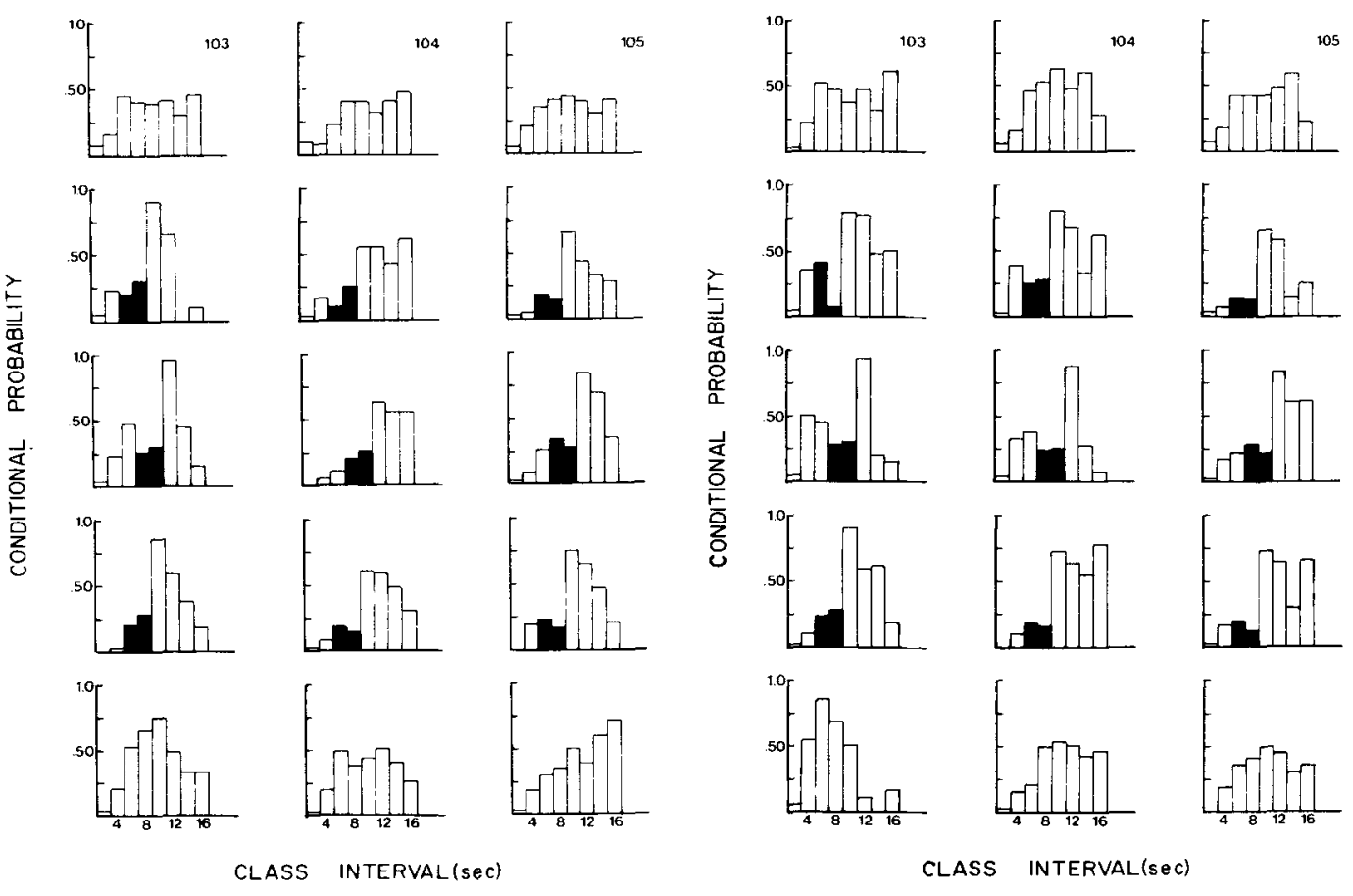

Figure 3. Mean conditional probability of a response to the $\mathrm{CO}$ key as a function of time elapsed since the previous $\mathrm{CO}$ in Experiment 2. Upper limit of eight consecutive 2-sec class intervals is shown on the $\mathrm{x}$-axis. Nochoice intervals are shown by the filled bars. Data from the red component are on the left panel; data from the green component are on the right panel.

the right panel. The class intervals that represent the no-choice intervals are filled. Only the responses that initiated the amber stimulus are represented in nochoice intervals; subsequent responses to the CO key during the amber stimulus are reported separately (see below).

During baseline, all subjects showed fairly constant conditional probability of a $\mathrm{CO}$, except in the first two class intervals, which showed low conditional probabilities. When no-choice intervals were scheduled (Phases 2-4), all subjects showed reduction in the conditional probability of a response to the $\mathrm{CO}$ key during no-choice intervals. Conditional probability of a $\mathrm{CO}$ was high immediately following the no-choice interval for all subjects in all no-choice conditions and showed decreasing trends thereafter, in most cases. There were changes in the conditional probability of a $\mathrm{CO}$ in the class intervals preceding the no-choice interval, suggesting shifts toward briefer or greater ICT durations than were reflected in Phase 1. There were between-subject differences in the direction and magnitude of these shifts, as well as within-subject differences across phases.

Figure 4 shows both the proportion of time spent in the no-choice interval when the amber feedback stimulus was on and the proportion of responses to the CO-key during the no-choice interval that were made in the presence of the amber stimulus. Propor-
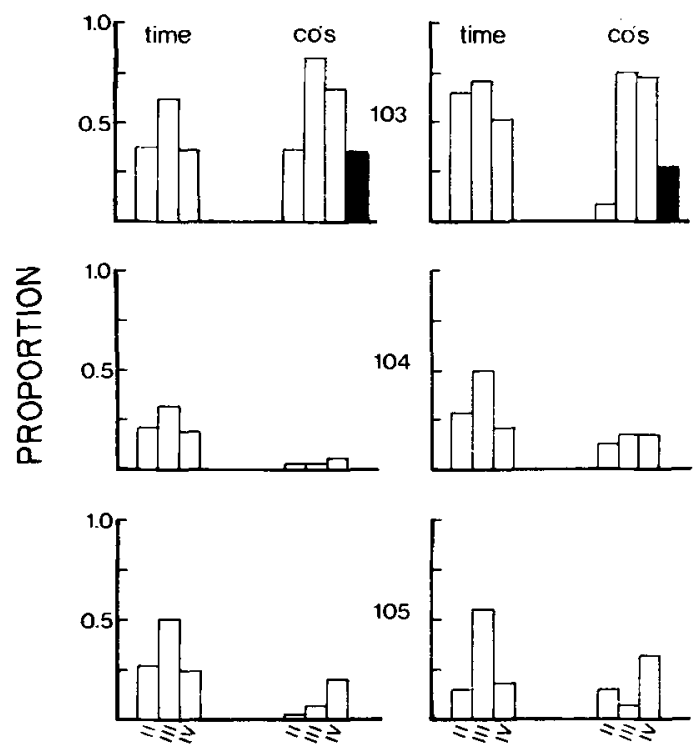

CONDITION

Figure 4. Mean proportion of time spent in the no-choice interval that the amber stimulus was on and proportion of responses to the $\mathrm{CO}$ key during the no-choice interval made in the presence of the amber stimulus for Phases 2-4 of Experiment 2. Data from the correction procedure for B-103 are shown by the filled bars. Data from the red component are on the left panel; data from the green component are on the right panel. 
tions represent the means from the last three sessions in each condition. Data for the red component are on the left; data for green are on the right. For B-103, data from the correction procedure are shown by the filled bars. All subjects spent proportionally more time in the no-choice interval in the presence of the feedback stimulus during the 6-10-sec no-choice condition. In addition, all subjects spent approximately the same proportion of time in the presence of the feedback stimulus during both exposures to the 4-8sec no-choice interval. With the exception of B-103, the subjects spent little time in the presence of the feedback light and made few of their responses to the $\mathrm{CO}$ key when the feedback stimulus was present, indicating that the feedback light exerted control over subsequent $\mathrm{CO}$ responding. In the case of B-103, the amber stimulus failed to suppress responding to the CO key even though the no-choice contingency produced obvious reorganization of ICTs (see Figure 3). In fact, the frequency of responding during amber increased perceptibly in both components after Phase 2. The discrepancies between the greencomponent data and the red-component data for this subject were greater than those of the other two subjects. The performance of B-103 in relation to the cue light, then, reflects something other than simple failure to discriminate no-choice intervals. Data from the correction procedure for B-103 show that the addition of a requirement to withhold responses to the $\mathrm{CO}$ key during the amber stimulus effectively reduced the number of responses during the amber stimulus.

\section{Discussion}

Experiment 2 demonstrated that the presence of discrete periods of extinction for $\mathrm{CO}$ responses can alter the probability that a $\mathrm{CO}$ response will occur in successive intervals since the previous $\mathrm{CO}$. The finding that subjects distributed their ICTs around nochoice intervals suggests that the time elapsed since the last $\mathrm{CO}$ response is a discriminable feature of performance on concurrent schedules. It is possible, therefore, that the characteristic temporal distribution of COs (Heyman, 1979; Menlove, 1975) on conc VI VI schedules is not a fundamental property of $\mathrm{CO}$ responding per se, but a property of behavior maintained by a given set of schedule contingencies. This result need not be viewed as antagonistic to a molar matching framework. Herrnstein and Loveland (1975) suggested that subjects could demonstrate sequential response strategies when choice behavior was under the control of inhomogeneities in reinforcement probability and yet match within like instances of inhomogeneity. While not specifically the type of inhomogeneity that Herrnstein and Loveland (1975) address, it is possible that their account could be generalized to the inhomogeneity in the effects of
$\mathrm{CO}$ responses introduced by the no-choice contingency. Furthermore, the demonstration that pigeons are capable of discriminating contingencies that vary in an orderly way with their local time allocation and of reorganizing their ICTs according to a local response rule does not imply that they do so on unadulterated concurrent schedules. Similarly, a demonstration that molar matching is unchallenged by the present results does not necessarily imply that they do not.

However, these data suggest the possibility that features of conc VI VI schedules that vary with ICT duration could be salient to the subject and could control local time allocation. The assumption that such control exists is a fundamental premise of momentary maximization theories (Shimp, 1982; Silberberg et al., 1978). Although the data do not provide direct support for a momentary maximization view of concurrent performance, they do provide evidence for an orderly and conditionable underlying structure to $\mathrm{CO}$ behavior maintained by concurrent schedules. The data also extend the findings that CO-contingent punishment (Todorov, 1971) and no-go multiple schedule stimuli (Experiment 1) suppress $\mathrm{CO}$ rate by demonstrating that particular classes of ICTs can be selectively suppressed by extinction contingent on ICT duration. Those instances when the no-choice contingency produced increases in the conditional probability of a $\mathrm{CO}$ prior to nochoice intervals suggest that a general suppressive effect of the no-choice contingency would not account for the present findings.

\section{GENERAL DISCUSSION}

The present studies indicate that pigeons can discriminate both signaled noncontingent and unsignaled contingent intervals during which $\mathrm{CO}$ responding is ineffective. Both experiments found that $\mathrm{CO}$ responding could be suppressed during discrete intervals without the arrangement of an explicit correlation between $\mathrm{CO}$ behavior and main-key reinforcement (cf. Pliskoff \& Green, 1972). It appears likely, therefore, that $\mathrm{CO}$ responding is maintained, at least in part, by its direct consequence: the change of schedule components.

\section{REFERENCES}

BAUM, W. M.The correlation-based law of effect. Journal of the Experimental Analysis of Behavior, 1973, 20, 137-153.

DE VILLIE Rs, P. A. Choice in concurrent schedules and a quantitative formulation of the law of effect. In W. K. Honig \& J. E. R. Staddon (Eds.), Handbook of operant behavior. New York: Prentice-Hall, 1977.

Fetterman, J. G., \& StuBbs, D. A. Matching, maximizing and the behavioral unit: Concurrent reinforcement of response sequences. Journal of the Experimental Analysis of Behavior, $1982,37,97-114$.

Fleshler, M., \& Hoftman, H. S. A progression for generat- 
ing variable-interval schedules. Journal of the Experimental Analysis of Behavior, 1962, 5, 529-530.

Hale, J. M., \& Shimp, C. P. Molecular contingencies: Reinforcement probability. Journal of the Experimental Analysis of Behavior, 1975, 24, 315-321.

Herrick, R. M., Meyer, J. L., \& Korotkin, A. L. Changes in $S^{d}$ and $S^{\Delta}$ rates during the development of an operant discrimination. Journal of Comparative and Physiological Psychology, 1959, 52, 359-363.

Heranstein, R. J. On the law of effect. Journal of the Experimental Analysis of Behavior, 1970, 13, 243-266.

Herrestein, R. J., \& Heyman, G. M. Is matching compatible with reinforcement maximization on concurrent variable-interval variable-ratio? Journal of the Experimental Analysis of Behavior, 1979, 31, $209-223$.

Herrnstein, R. J., \& Loveland, D. H. Maximizing and matching on concurrent ratio schedules. Journal of the Experimental Analysis of Behavior, 1975, 24, 107-116.

HEYMAN, G. M. Markov model description of changeover probabilities on concurrent variable-interval schedules. Journal of the Experimental Analysis of Behavior, 1979, 31, 41-51.

Heyman, G. M., \& LuCE, R. D. Operant matching is not a logical consequence of maximizing reinforcement. Animal Learning \& Behavior, 1979, 7, 133-140.

MEnLove, R. L. Local patterns of responding maintained by concurrent and multiple schedules. Journal of the Experimental Analysis of Behavior, 1975, 23, 309-337.

Nevin, J. A. Overall matching versus momentary maximizing: Nevin (1969) revisited. Journal of Experimental Psychology: Animal Behavior Processes, 1979, 5, 300-306.

Pliskofr, S. S. Effects of symmetrical and asymmetrical changeover delays on concurrent performances. Journal of the Experimental Analysis of Behavior, 1971, 16, 249-256.

Pliskoff, S. S., \& Green, D. Effects on concurrent performances of a stimulus correlated with reinforcer availability. Journal of the Experimental Analysis of Behavior, 1972, 17, 221-227.

RACHLIN, H. A molar theory of reinforcement schedules. Journal of the Experimental Analysis of Behavior, 1978, 30, 345-360.
SHImP, C. P. Optimal behavior in free-operant experiments. Psychological Review, 1969, 76, 97-112.

Shimp, C. P. Perspectives on the behavioral unit: Choice behavior in animals. In W. K. Estes (Ed.), Handbook of learning and cognitive processes (Vol. 2). Hillsdale, N.J: Erlbaum, 1975.

Shimp, C. P. Reinforcement and the local organization of behavior. In R. J. Herrnstein \& M. Commons (Eds.), Quantitative analyses of operant behavior (Vol. 2): Matching and maximizing accounts. New York: Ballinger, 1982.

Silberbeng, A., \& Fantino, E. Choice rate of reinforcement and changeover delay. Journal of the Experimental Analysis of Behavior, 1970, 13, 187-197.

Silberberg, A., Hamilton, B., Ziriax, J. M., \& Casey, J. The structure of choice. Journal of Experimental Psychology: Animal Behavior Processes, 1978, 4, 368-398.

Stubss, D. A. Temporal discrimination and a free-operant psychological procedure. Journal of the Experimental Analysis of Behavior, 1980, 33, 167-185.

Stubss, D. A., Puiskoff, S. S., \& Reid, H. M. Concurrent schedules: A quantitative relation between changeover behavior and its consequences. Journal of the Experimental Analysis of Behavior, 1977, 27, 85-96.

Todorov, J. C. Concurrent performances: Effect of punishment contingent on the switching response. Journal of the Experimental Analysis of Behavior, 1971, 16, 51-62.

\section{NOTE}

1. Two subjects (B-103 and B-105) were initially exposed to a condition that was similar in all respects, with the exception that no feedback was provided, for approximately 10 experimental sessions. For these two subjects, then, the baseline condition and the first no-choice condition reported here were not contiguous.

(Manuscript received August 3, 1982; revision accepted for publication January 19,1983 .) 